Orbis Tertius, vol. XXII, n 26 , e056, diciembre 2017. ISSN 1851-7811

Universidad Nacional de La Plata

Facultad de Humanidades y Ciencias de la Educación

Centro de Estudios de Teoría y Crítica Literaria

\title{
Lectores y lectura: cinco intervenciones
}

\author{
Verónica Delgado, Juan Ennis, Margarita Merbilhaá, Hernán Pas
}

El IX Congreso Internacional Orbis Tertius, organizado en junio de 2015, quiso celebrar un homenaje a Susana Zanetti, quien fue durante tres décadas Profesora Titular de Literatura Latinoamericana en nuestra Facultad, la primera directora del Departamento de Letras tras la renovación de la carrera que tuvo lugar al finalizar la última dictadura militar y que, entre otras actividades, formó a muchos de los actuales docentes e investigadores del Centro de Teoría y Crítica Literaria, donde dirigió también esta misma revista. Lectora voraz y creativa, Susana Zanetti nos había dejado un legado crítico perdurable en sus clases y escritos. Su magisterio, no obstante, alcanza no sólo a alumnos, discípulos y colegas, sino que abrió un mundo a miles de lectores. Cualquiera que recuerde -o sin poder recordar, encuentre, hoy, en bibliotecas públicas y privadas, en librerías de usados- el valor de una empresa como la del Centro Editor de América Latina, sabrá de qué estamos hablando. En homenaje, entonces, a su legado de lectora, el comité científico del CTCL propuso, entre los objetivos del evento, indagar el campo de los estudios literarios relativos a la lectura y los lectores.

Dos orientaciones principales organizaron el territorio de las investigaciones que este Congreso procuró compartir y discutir: por una parte, la lectura y las subjetivaciones-desubjetivaciones que llamamos "lector" en términos de experiencia y acontecimiento -según recorridos de la teoría literaria, la filosofía y la propia literatura, que van de Derrida y de De Man a Miller, de Barthes a Badiou, de Proust y Virginia Woolf a Borges y María Moreno. Por otra parte, las investigaciones de las llamadas historias de la lectura y los lectores, que desde enfoques sociológicos, culturalistas o historiográficos interrogan el tema en tanto prácticas y sujetos socialmente constituidos y determinados; las firmas de Chartier, Darnton, Mollier, Petrucci, a la vez que las de Adolfo Prieto, Nora Catelli, Beatriz Sarlo, Susana Zanetti o Graciela Batticuore orientan buena parte de este campo de investigaciones, que permite abordar el problema de la historia de la edición y los mercados, la divergencia públicos/lectores, lectores/lectoras, lectores de prensa y lectores de libros; el problema de las representaciones literarias de la lectura como resto de experiencia o como práctica cultural, la lectura en la ficción, en el teatro y en la poesía. Tales orientaciones no excluían las posibles revisiones de otros clásicos de la crítica, la teoría literaria y la filosofía asociados con la semiótica, la estética de la recepción, la hermenéutica u otras tradiciones (McKenzie, Eco, Febvre, Iser, Fish, Gadamer, Jauss, entre otros).

En torno a estos debates y sus ramificaciones, se organizaron dieciocho simposios con más de 400 ponencias de investigadores de un sinnúmero de universidades del país y el exterior. La mayor parte de esos trabajos han sido

Cita sugerida: Delgado, V., Ennis, J., Merbilhaá, M. y Pas, H. (2017). Lectores y lectura: cinco intervenciones. Orbis Tertius, 22(26), e056. https://doi.org/10.24215/18517811e056 
publicados online como actas del IX Congreso Internacional de Teoría y Crítica Literaria "Orbis Tertius": Lectores y Lectura. Homenaje a Susana Zanetti, y pueden consultarse en la página web del mismo: http://citclot.fahce.unlp.edu.ar/actas-publicadas

En este dossier hemos reunido cinco conferencias expuestas por algunos de los invitados especiales del Congreso. Ellas ofrecen, en cierto modo, un panorama de los temas y problemas propuestos en sus lineamientos generales. Nos complace que una de las conferencias, la de María Teresa Gramuglio, sea en sí misma un modo de homenajear a Susana Zanetti, pues en ella la autora recordó los continuos intercambios que a lo largo de sus años de docencia y escritura, tuvo con su tan querida amiga y colega, y por eso hemos decidido situarla en primer lugar, como puerta de ingreso a un espacio de discusión que se abrió antes, mucho antes de este congreso, gracias a esa práctica crítica cultivada en el diálogo y el debate, a la que aquí quisimos rendir tributo.

En su conferencia, Gramuglio presenta un recorrido bibliográfico de la obra de Susana Zanetti desde una perspectiva de la crítica, en este caso de la crítica comparada, que no desmerece la anécdota personal, el recuerdo, ni los detalles evocativos de la personalidad de la homenajeada. A partir de la selección de un corpus de la obra crítica de Zanetti, la relectura que se esboza en este ensayo apunta a poner de relieve sus aciertos e iluminaciones críticas, sus puntos de inflexión y vínculos con la crítica latinoamericana y con el modelo comparatístico.

En segundo lugar se encuentra la conferencia de Juan Poblete "Qué es, qué fue y cuál es el futuro de la lectura". Poblete reabre algunas preguntas que desde el presente, resulta necesario volver a plantearse: ¿Qué es, qué fue y cuál es el futuro de la lectura? ¿Qué es la lectura como tal, en cuanto actividad que involucra las funciones cognitivas y el cuerpo? En segundo lugar, ¿qué ha sido la lectura históricamente?, ¿cómo ha evolucionado, cómo ha sido usada, por quién, con qué efectos y en qué contextos? Finalmente, ¿cuál podría ser su condición actual y su futuro? Revisando un sustancial corpus de bibliografía especializada, que va desde las reflexiones de Mark Bauerlein sobre las plataformas digitales y su incidencia en las modalidades lectoras y narrativas, pasando por enfoques más clásicos pero no por ello menos sustanciales como los de Nancy Armstrong y Karin Littau alrededor de los deseos y corporalidades de la lectura, hasta algunos autores menos visitados como Jonathan Beller y Giles Slade, que aportan la perspectiva narrativa del cine y las nuevas tecnologías mediáticas, Poblete va hilvanando un sólido argumento a favor de la lectura literaria recompensada con las nuevas plataformas de la era digital y en contra de las visiones apocalípticas que le adjudicaban una perentoria y resignada extemporaneidad.

En "Otras voces y otros ámbitos para la Historia de la Lectura”, Alejandro Parada propone, a modo de desafío epistemológico, volver sobre algunas preguntas generales, fundantes de la historia de la disciplina, para luego señalar líneas que considera aun no exploradas y a las que define, reformulando el título de una novela de Truman Capote, como "Otras voces y otros ámbitos para la Historia del Libro".

Parada traza un balance inicial de los problemas de investigación de la Historia del Libro, que van desde el objeto de estudio y los distintos enfoques, hasta la caracterización de los documentos y por último, los diálogos que la Historia de libro estableció con otras disciplinas de las ciencias sociales. Luego de este balance, llama la atención sobre aquello que considera, en las bases de la disciplina, el ámbito "evasivo" del acto de leer y sus efectos sobre los individuos. Aquí aparece un inevitable carácter conjetural del discurso de la disciplina, que avanzaría por aproximaciones frente al "misterio encriptado en distintos devenires”, imposible de estabilizar. ¿De qué modo, entonces, abordar la lectura en tanto acto, más allá de los avances actuales de los estudios sobre el libro? Las respuestas parecen orientarse hacia los modos de la subjetivación y su vínculo con las prácticas lectoras, modos múltiples en los que el autor invita a pensar tanto en operaciones de conceptualización como en el papel de la imaginación, la fantasía y lo lúdico (en los términos abiertos por las reflexiones de Huizinga) en el mismo acto de leer. Estas preguntas llevarían a explorar con los lectores, y a pensarlos como posibles conceptualizadores, creadores de hipótesis teóricas en torno a la actividad lectora.

Juan Ritvo llama la atención sobre la singularidad de que un vocablo tan anodino como el verbo "leer", carente de los brillos de otros términos, ahora sospechosos otrora magníficos - interpretar, actividad hermenéutica, exégesis 
- se haya expandido del modo en que lo hecho. Plantea así el interrogante acerca de la profunda insatisfacción que su uso pareciera deparar, y sobre todo por lo aparentemente ilimitado de su alcance, ya que abarca a la crítica, a la hermenéutica filosófica -o bíblica, o historiográfica-, alcanzando a través de un desplazamiento metonímico inevitable a la voz y a la escritura y a la historia multisecular que domina los vínculos entre el habla y la escritura. Leemos, según Ritvo, porque hay grietas profundas e incolmables en el orden del saber, grietas que ningún dispositivo hermenéutico puede suturar. Claro. Pero sobre todo leemos, porque hay una experiencia histórica que inició ese movimiento de conversión propio de nuestra época y que Nietzsche captó, llamándolo, para diferenciarlo de una actitud blanda, pasiva, nihilismo activo.

Finalmente, el trabajo Fernando Degiovanni focaliza en el modo en que la lectura ha sido puesta en imágenes. Parte de la tradición específica del género "retrato de lectores", que encuentra modulaciones específicas en los cultores argentinos del género en el siglo XIX, y que sufrirá drásticas variaciones en el siglo XX. Toma como objeto tres obras de Antonio Berni correspondientes a distintos momentos de su producción artística (Chacareros, de 1935; Juanito Laguna aprende a leer, 1961; Juanito dormido, 1978), las cuales más allá de participar de alguna convenciones del género, son consideradas ficciones visuales con impresos puesto que constituyen narraciones con personajes.

El análisis se concentra en los cuerpos y en los espacios, desde una mirada que privilegia las relaciones entre cultura y sociedad, para dar cuenta de esos vínculos, en el cruce entre modernidad y capitalismo, y leer en esas obras los avatares de lectores y lectura, precisando sus contextos políticos- culturales.

Cinco conferencias, cinco enfoques, cinco recortes diversos sobre un problema común, si no síntesis al menos muestra generosa de la experiencia del IX Congreso “Orbis Tertius”, del abanico de posibilidades que para la pregunta allí planteada ofrece la crítica hoy y aquí, aunque no sólo eso. También, volviendo al comienzo, se trata también de una forma de completar ese homenaje, alojando en la revista que la homenajeada dirigió un testimonio no sólo de las huellas precisas de su influencia en cuanto a hipótesis, certezas, intuiciones, modos de lectura, sino además de una de las formas quizás más fecundas de dejar aquí, entre nosotros, en nuestras instituciones y tradiciones de trabajo intelectual, eso que damos en llamar un legado: la generación de un espacio amplio, diverso, complejo y atravesado de tensiones para trabajar y debatir lo que, al fin y al cabo, probablemente más nos guste, la lectura. 